\title{
Key Members' Impact on Ecosystem Niche Creation: An Empirical Study on Shanzhai Ecosystem
}

\author{
Jie Hou ${ }^{1, a}$ \\ ${ }^{1}$ Shenzhen Polytechnic, Xili Lake, Nanshan District, Shenzhen, Guangdong Province, P.R.China \\ a595131976@qq.com \\ * Jie Hou
}

Keywords: Business ecosystem, Niche creation, Shanzhai.

\begin{abstract}
Keystones, dominators, government are key members in business ecosystem. This paper examines the impact of these key members on niche creation rate in shanzhai business ecosystem. By employing negative binomial regression, this paper analyzed the shanzhai business ecosystem with 9957 registered mobile-communication firms in Shenzhen between 1984-2011. The results show that, keystone company has significantly increasing positive impact on the founding rate of this mobile phone population, while the dominator's effect is decreasing; the technology patent population and the policy also have significantly positive impacts on the founding rate of the population.
\end{abstract}

\section{Introduction}

New ventures are important to a country. Davis and Haltiwanger (1990) pointed out that they provided 20\% of new jobs each year[1]. Moore(2006) defined business ecosystem as a niche network with a lot of interacted organizations and individuals in it[2], and niche creation is one of the three important indicators of business ecosystem health[3].

Similar with natural ecosystem, some companies in business ecosystem have a crucial impact on the entire ecological network, just like coral's importance to its ecosystem in the ocean. In the supply chain network, if there is an absence of strong core companies in the network, the efficiency of the supply network will be reduced[4]. On the other hand, these key members usually have the core resources, their different strategies will decisively influence the creation, profitability, and growth of new ventures in the ecosystem. So this study tried to examine the key members' impact on ecosystem niche creation with an empirical study on shanzhai mobile phone ecosystem in Shenzhen, China.

\section{Theory and hypothesis}

The concept of business ecosystem is widely used by large multi-national enterprises, such as Microsoft, ARM, Intel, HP, Wal-Mart, most of them have specialized ecosystem management department. Companies like them usually occupied the core niche of the ecosystem, by nurturing and taking advantage of more and more important niches to enhance their competitiveness, Iansiti and Levien,(2004)called them Keystones[3].Keystones are the most important members in business ecosystem, they provide a stable, predictable platform for other members to survive and grow, so when a keystone arise in a business ecosystem, accompanied by continuous improvement of its platform and emerging business opportunities, the number of new ventures in ecosystem will burst.

Hypothesis la: Niche creation rate will rise with the appearance of the keystone.

Hypothesis 1b: The positive effect from the keystone will increase over time after its appearance.

However, not all of the companies in core niche have the positive impact on ecosystem, market turbulence generate by certain core companies can generate financial losses and exit for niche market firms[5]. Some companies took advantage of its core niche positon, pursued short-term benefit maximization through vertical, horizontal integration and changed the market thresholds. Iansiti and Levien(2004)called them Dominator[3]. 
Hypothesis 2a: The appearance of the dominators will have no positive effect on niche creation rates.

Hypothesis $2 b$ : There will be no increasing positive effect on niche creation rates after dominator's appearance.

Technology life cycle is also of crucial importance to ventures creation and mortality rates[6].It was believed that technology changes would bring industrial risks and uncertainties, which might reduce new ventures creation probability and raise mortality[7].

Hypothesis 3: Technology patents populations have positive effect on the niche creation of relevant business ecosystem.

Government agencies and policy makers are divided into the important members in a business ecosystem, Price(1995)and Powell (2005)'s studies showed that government policy are important to the evolution of the enterprise population[8,9].

Hypothesis 4: Government policies have positive effect on niche creation rates.

\section{Research design}

\subsection{Data}

Shenzhen is the most famous base on mobile phone production and export, and is well-known by the shanzhai mobile phone ecosystem which based on MTK chips. Using database from Shenzhen market administration, we collected 9957 related new ventures register data between 1984-2011, which is the life cycle of shanzhai mobile phone ecosystem. Patent data came from Derwent Publications Ltd. Patent Retrieval System.

\subsection{Model}

New ventures creation rates are nonnegative, has discontinuous distribution, and do not subject to Gaussian distribution, so Poisson regression is widely used to study variables of this class, especially in organizational ecology research $[10,11]$. The basic Poisson regression model for event count data is:

$$
\operatorname{Pr}\left(\mathrm{Y}_{t}=\mathrm{y}\right)=e^{\lambda\left(x_{t}\right)}\left[\lambda\left(x_{t}\right)^{y} / \mathrm{yl}^{\mathrm{l}}\right]
$$

$\operatorname{Pr}\left(\mathrm{Y}_{\mathrm{t}}=\mathrm{y}\right)$ is the expected number of events, $\lambda\left(\mathrm{x}_{\mathrm{t}}\right)$ is the variance of the number of events, it has to be interval equal rate. But for count data on new ventures creation, the variance often exceed the mean[11], so we followed earlier research, used negative binomial regression model[7], which allows Poisson process to include heterogeneity by relaxing the assumption that the mean and variance are equal, formulation is:

$$
\lambda_{t}=\exp \left(\beta x_{t}\right) \varepsilon_{t}
$$

Where the error term $\varepsilon_{t}$ follows a $\gamma$ distribution.

\section{Theory variables}

\subsection{Dependent variables}

Niche creation: We used register time as the creation time of a new venture, and took half year as an observation period to collect the creation number of each observation period.

\subsection{Covariant}

Keystones emerging: MTK is well-known as the keystone of shanzhai mobile phone ecosystem[12].MTK provided a 'turn-key' platform for niche companies developing their products, and kept its chip technology updating smooth and steady, to avoid putting any plague to niche companies. Although MTK occupied the core niche of ecosystem, it still paid much attention to 
nurturing niche companies, provided strong technology support to niche companies and shared value with them. We used dummy variable to measure its emerging. From2005, MTK's chip was widely used in shanzhai mobile phone ecosystem, so we assigned the value 1 to dummy variable after 2005, and 0 before 2005 .

Keystone emerging clock: we set a time-clock to examine the possibility that the keystone's impact may varied over time. It counted the natural logarithm of the number of period since keystones emerging.

Dominator emerging: Since the year of 1998, Nokia became No.1 in mobile phone market, and it tried to cover all the market segment in order to maximize short-term profits. In 2006, Nokia purchased the whole Symbian OS to make it only serve Nokia itself. Through suppressing other members, no matter large or small companies in the mobile phone ecosystem, Nokia kept holding $40 \%$ of the global mobile phone market share. Until 2008, Apple and Android ecosystem obtained fast progress, Nokia's dominant position started to fall. So we assigned the value 1 to a dummy variable between 1998-2008, and 0 for other years.

Dominator emerging clock: Same as keystones emerging clock.

Patent population: Shanzhai mobile ecosystem relied mainly on the second generation communication technologies(GSM), so we counted GSM related patent number under index W-Communications in Derwent Publications Ltd. Patent Retrieval System and take the logarithm.

Government policy: China's mobile phone license system is the typical and most important policy during this period. According to the policy, from 1998 to 2004, only 11 large enterprise had license of mobile phone production, a lot of small enterprise had to do the OEM production for them. So we assigned the value 1 to a dummy variable between 1998-2004, and 0 for other years.

\subsection{Control variable}

Labor cost: Wages level has significant impact on new ventures creation[13],we use the index of real wages in Shenzhen statistical yearbook to measure the labour cost.

Prior venture creations: Population density and prior venture creations also has significant impact on new ventures creation[14],we use the previous year creation numbers to measure the variable.

Economic crisis: As we know, worldwide economic crisis emerged in 2008, we assigned the value 1 to a dummy variable for 2008 , and 0 for other years.

\section{Result and Discussion}

Data description is shown in Table 1, we use nested regression models and Likelihood chi-square value $\mathrm{G}^{2}$ to avoid multicollinearity[14].

Table1. Data description.

\begin{tabular}{cccccc}
\hline & N & Minimum & Maximum & Mean & $\begin{array}{c}\text { Standard } \\
\text { deviation }\end{array}$ \\
\hline Niche creation & 56 & 0 & 1366 & 177.8 & 292.776 \\
\hline Keystone emerging & 56 & 0 & 1 & 0.29 & 0.456 \\
\hline Keystone emerging clock & 56 & 0 & 16 & 2.429 & 4.604 \\
\hline Dominator emerging & 56 & 0 & 1 & 0.25 & 0.437 \\
\hline Dominator emerging clock & 56 & 0 & 10 & 0.9824 & 2.4534 \\
\hline Patent population & 56 & 0 & 7.22 & 4.445 & 2.3584 \\
\hline Government policy & 56 & 0 & 1 & 0.32 & 0.471 \\
\hline Economic crisis & 56 & 0 & 1 & 0.04 & 0.187 \\
\hline Labor cost & 56 & 154 & 844.9 & 397.753 & 225.088 \\
\hline Prior venture creations & 56 & 0 & 911 & 134.91 & 214.323 \\
\hline
\end{tabular}

By using nested regression models, Variables were divided into four groups, and substituted into regression model in turn, so we got 4 models. The results were showed in Table2. 
In model 1, Keystone emerging and its clock have positive correlation with niche creation rate. The significance level is $.000<0.001$, so MTK, as the keystone of shanzhai mobile phone ecosystem, has great contribution to the improvement of ecosystem health, and we can get the same conclusions from model 2-4. Hypothesis $1 \mathrm{a}$ and $1 \mathrm{~b}$ was supported.

Dominator emerging and its clock were added from model 2, and $G^{2}=58.022$, which is larger than the critical value $\left[\chi_{0.001}^{2}(2)\right]=13.81$, so model 2 was improved with these 2 variables' adding. Model 2 shows that Nokia has positive correlation with niche creation rate, but the effect was decreasing along with time, model 3-4 show the same result. We believe that the particular characteristic of shanzhai mobile phone ecosystem led to the result. There were lots of small companies in the ecosystem. In addition to the production of mobile phone, most of them also produced peripheral products of mobile phone, such as cell, charger, earphone, etc. Nokia's $40 \%$ of mobile phone market share would bring a large niche market. Along with the decline of Nokia, the positive effect was reducing inevitably. Hypothesis $2 \mathrm{a}$ was not supported, $2 \mathrm{~b}$ was supported.

Patent population and government policy were added from model $3, G^{2}=66.104$, which means these two variable contribute more explains to the model. Patent population's positive correlation means that continuous improvement in one technology lifecycle will create more niche market for new ventures to survive. We can also see that China's mobile phone license system indeed protected the emerging mobile phone industry, and standardized the order of market competition. Hypothesis 3 and 4 was supported.

Table2. Four model result

\begin{tabular}{|c|c|c|c|c|}
\hline Variable & Model 1 & Model 2 & Model 3 & Model 4 \\
\hline Keystone emerging & $\begin{array}{c}1.906 * * \\
(.000)\end{array}$ & $\begin{array}{c}1.040 * * \\
(.000)\end{array}$ & $\begin{array}{c}0.423^{* *} \\
(.004)\end{array}$ & $\begin{array}{c}0.375^{*} \\
(.033)\end{array}$ \\
\hline Keystone emerging clock & $\begin{array}{c}0.109 * * \\
(.000)\end{array}$ & $\begin{array}{c}0.246 * * \\
(.000)\end{array}$ & $\begin{array}{c}0.232 * * \\
(.000)\end{array}$ & $\begin{array}{c}0.094 * \\
(.006)\end{array}$ \\
\hline Dominator emerging & & $\begin{array}{c}2.523 * * \\
(.000)\end{array}$ & $\begin{array}{c}0.945 * * \\
(.000)\end{array}$ & $\begin{array}{c}0.722 * * \\
(.000)\end{array}$ \\
\hline Dominator emerging clock & & $\begin{array}{c}-0.182 * * \\
(.000)\end{array}$ & $\begin{array}{c}-0.138 * * \\
(.000)\end{array}$ & $\begin{array}{c}-0.130 * * \\
(.000)\end{array}$ \\
\hline Patent population & & & $\begin{array}{c}0.516 * * \\
(.000)\end{array}$ & $\begin{array}{c}0.258 * \\
(.002)\end{array}$ \\
\hline Government policy & & & $\begin{array}{c}0.891 * * \\
(.000)\end{array}$ & $\begin{array}{c}0.846 * * \\
(.000)\end{array}$ \\
\hline Prior venture creations & & & & $\begin{array}{l}0.001 * \\
(.004)\end{array}$ \\
\hline Labor cost & & & & $(0 . \overline{326})$ \\
\hline Economic crisis & & & & $(0.690)$ \\
\hline Log-likelihood & -277.728 & -248.717 & -215.665 & -210.658 \\
\hline $\begin{array}{l}\text { Perarson } \\
\text { chi-square }\end{array}$ & 612.581 & 224.427 & 50.888 & 43.192 \\
\hline Df & 2 & 4 & 6 & 8 \\
\hline chi-square likelihood (Omnibus) & $119.043 * *$ & $177.065 * *$ & $243.169 * *$ & $255.730 * *$ \\
\hline$G^{2}$ & & $\begin{array}{c}58.022>13.81 \\
{\left[\chi_{0.001}^{2}(2)\right]}\end{array}$ & $\begin{array}{c}66.104>13.81 \\
{\left[\chi_{0.001}^{2}(2)\right]}\end{array}$ & $\begin{array}{c}12.561<13.81 \\
{\left[\chi_{0.001}^{2}(2)\right]} \\
12.561>5.99 \\
{\left[\chi_{0.05}^{2}(2)\right]}\end{array}$ \\
\hline
\end{tabular}

Control variable: Labor cost and economic crisis failed to pass the test of significance, explains that wage level had not been an important factor in Shenzhen before 2011. Without the two variable, 
the model showed that prior venture creation rate has positive correlation with niche creation rate, which means the number of niche companies had not reach environmental capacity limit, and prior ventures created more business opportunities and skilled employees for the new ventures.

The result of this study shows that keystone, technology and government policy are of importance to business ecosystem health. Compared with the direct subsidies to ventures in an emerging industry, selecting and assisting a responsible keystone are much more important for the government.

\section{Acknowledgement}

This study is supported by Guangdong Province Natural Science Foundation (No. 2015A030310525) .

\section{References}

[1] S. J. Davis and J. Haltiwanger, "Gross job creation and destruction: Microeconomic evidence and macroeconomic implications,": MIT Press, 1990.

[2] J. F. Moore, Business ecosystems and the view from the firm vol. 51, 2006.

[3] M. Iansiti and R. Levien, The keystone advantage: Harvard Business School Press, 2004.

[4] Shihua Ma, " The Influence of Core Enterprise on The Formation of Strategic Partnership in Supply Chain " Industrial Engineering and Management, pp. 24-27, 2000-02-10 2000.

[5] L. Pierce, "Big losses in ecosystem niches: How core firm decisions drive complementary product shakeouts," Strategic Management Journal, vol. 30, pp. 323-347, 2009.

[6] M. L. Tushman and P. Anderson, "Technological discontinuities and organizational environments," Administrative science quarterly, pp. 439-465, 1986.

[7] J. A. C. Baum, H. J. Korn and S. Kotha, "Dominant designs and population dynamics in telecommunications services: Founding and failure of facsimile transmission service organizations, 1965-1992," Social Science Research, vol. 24, pp. 97-135, 1995.

[8] G. N. Price, "The determinants of entry for black-owned commercial banks," The Quarterly Review of Economics and Finance, vol. 35, pp. 289-303, 1995.

[9] W. W. Powell, D. R. White, K. W. Koput, and J. Owen Smith, "Network Dynamics and Field Evolution: The Growth of Interorganizational Collaboration in the Life Sciencess," American journal of sociology, vol. 110, pp. 1132-1205, 2005.

[10]J. A. C. Baum and J. V. Singh, "Organizational niches and the dynamics of organizational mortality," American Journal of Sociology, pp. 346-380, 1994.

[11]J. Ranger-Moore, J. Banaszak-Holl and M. T. Hannan, "Density-dependent dynamics in regulated industries: Founding rates of banks and life insurance companies," Administrative Science Quarterly, pp. 36-65, 1991.

[12]K. Rong, Z. Liu and Y. Shi, "Reshaping the business ecosystem in China: case studies and implications," Journal of Science \& Technology Policy in China, vol. 2, pp. 171-192, 2011.

[13]C. M. Campbell, "The effects of state and industry economic conditions on new firm entry," Journal of Economics and Business, vol. 48, pp. 167-183, 1996.

[14]J. A. C. Baum and C. Oliver, "Institutional embeddedness and the dynamics of organizational populations," American Sociological Review, pp. 540-559, 1992. 